\title{
Biocontrole da antracnose em frutos de mamoeiro por bactérias epifíticas formadoras de biofilme
}

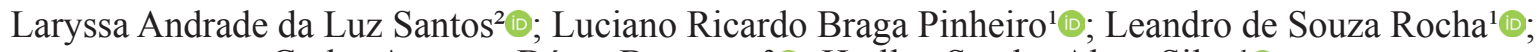 \\ Carlos Augusto Dórea Bragança ${ }^{2} \odot$; Harllen Sandro Alves Silva ${ }^{1}$
}

\begin{abstract}
${ }^{1}$ Empresa Brasileira de Pesquisa Agropecuária, Mandioca e Fruticultura, Rua Embrapa s/nº, Caixa Postal 007, CEP: 44.380-000, Cruz das AlmasBA, Brasil. ${ }^{2}$ Universidade Federal do Recôncavo da Bahia, UFRB, Rua Rui Barbosa, CEP: 44.380-000, Cruz das Almas-BA, Brasil.

Autor para correspondência: Laryssa Andrade Da Luz Santos (laryandradee@hotmail.com)

Data de chegada: 27/11/2018. Aceito para publicação em: 19/12/2019.
\end{abstract}

$10.1590 / 0100-5405 / 216998$

\section{RESUMO}

Santos, L.A.L.; Silva, H.S.A.; Pinheiro, L.R.B.; Rocha, L.S.; Bragança, C.A.D; Silva, H.S.A. Biocontrole da antracnose em frutos de mamoeiro por bactérias epifíticas formadoras de biofilme. Summa Phytopathologica, v.47, n.1, p.45-53, 2021.

A fim de se obter agentes de biocontrole para controle da antracnose em frutos de mamão em pós-colheita, buscou-se: i) selecionar bactérias epifíticas de mamoeiro antagonistas a Colletotrichum brevisporum pela produção de compostos antimicrobianos difusíveis e voláteis, quitinase e inibição da germinação de conídios; ii) quantificar a produção de biofilme pelos isolados selecionados; iii) obter uma concentração de bactérias que proporcionasse o controle da antracnose em discos de frutos; iv) avaliar a redução da severidade da doença em frutos de mamão. De 224 bactérias, 74 exibiram um mecanismo de ação contra o patógeno, 13 isolados dois mecanismos, quatro apresentaram três, e uma bactéria exibiu todos. Mediante a verificação da compatibilidade entre antagonistas, e a quantificação da formação de biofiolme, estabeleceram-se cinco "Mix" compostos por quatro isolados bacterianos. Em discos de frutos as bactérias foram avaliadas nas concentrações $10^{6}, 10^{7}$ e $10^{8}$ UFC $\mathrm{mL}^{-1}$. À exceção do Mix 2, os demais reduziram significativamente a antracnose nos discos quando comparados ao controle. Os "Mix" 1, 3, 5, na concentração $10^{8}$ UFC mL ${ }^{-1}$ exibiram melhor desempenho reduzindo a doença em até $75 \%$, 89,78\% e 90,8\%, respectivamente. Os Mix 3 e 5, na concentração de $108 \mathrm{UFC} \mathrm{mL}^{-1}$, foram avaliados em frutos juntamente com o fungicida sintético Piraclostrobina. Não se verificou diferença significativa entre os Mix e o fungicida, que atingiu níveis de redução da doença superiores a $97 \%$, e as combinações com $98 \%$, frente ao controle não tratado.

Palavras-chave: Carica papaya. Controle biológico. Colletotrichum brevisporum.

ABSTRACT

Santos, L.A.L.; Silva, H.S.A.; Pinheiro, L.R.B.; Rocha, L.S.; Bragança, C.A.D; Silva, H.S.A. Biological control of anthracnosis in papaya fruits by biofilm-forming epiphytic bacteria. Summa Phytopathologica, v.47, n.1, p.45-53, 2021.

Aiming to obtain biocontrol agents for post-harvest anthracnose control in papaya fruits, the present study sought to: i) select, from papaya fruits, epiphytic bacteria that are antagonistic to Colletotrichum brevisporum, based on the production of diffusible and volatile antimicrobial compounds, chitinase, and conidial germination inhibition; ii) quantify biofilm production by the selected strains; iii) obtain a concentration of bacteria that would provide anthracnose control in fruit discs; iv) evaluate the disease severity reduction in papaya fruits. Of 224 bacteria, 74 exhibited one mechanism of action against the pathogen, 13 isolates showed two mechanisms, four isolates had three mechanisms, and one bacterium showed all mechanisms. Verification of compatibility between antagonists, as well as biofilm quantification, led to the formation of five "Mix" composed of four bacterial isolates. In fruit discs, bacteria were evaluated at the concentrations $10^{6}, 10^{7}$ and $10^{8} \mathrm{CFU} \mathrm{mL}^{-1}$. Except Mix 2, the remaining combinations significantly reduced anthracnose in the discs when compared to control. Mix 1, 3 and 5, at the concentration $10^{8} \mathrm{CFU}$ $\mathrm{mL}^{-1}$, showed the best performance, reducing the disease severity by up to $75.0 \%, 89.78 \%$ and $90.8 \%$, respectively. Mix 3 and 5, at the concentration $10^{8} \mathrm{CFU} \mathrm{mL}^{-1}$, were evaluated together with the synthetic fungicide Pyraclostrobin in fruits. There was no significant difference between the Mix and the fungicide, which reached disease reduction levels superior to $97 \%$, while combinations reached $98 \%$, compared to the untreated control.

Keywords: Carica papaya. Biocontrol. Colletotrichum brevisporum.

O mamão é um fruto altamente perecível e suscetível a patologias pré e pós-colheita. Entre as principais doenças que acometem os frutos, a antracnose se destaca por limitar a vida útil dos frutos. Ainda que não apresentem sintomas quando colhidos, a doença se manifesta na fase de embalagem, durante o armazenamento e o transporte, tornando os frutos imprestáveis para a comercialização, causando significativo percentual de perdas.

Na maioria das vezes, a doença é associada ao fungo Colletotrichum gloesporioides, como agente causal. No entanto, este gênero apresenta um complexo de espécies associadas à antracnose, que são morfologicamente semelhantes, mas geneticamente distintas, as quais incitam o mesmo quadro sintomatológico (19).

No Brasil, apesar do considerável volume de frutos de mamão exportados, ainda persiste um desafio a ser superado no setor; abaixo de $10 \%$ do que é produzido é comercializado para outros países (14). Um dos principais entraves à expansão da comercialização internacional dos frutos são as barreiras rigorosas, impostas pelos importadores, tanto no sentido da presença de patógenos quanto de resíduos de defensivos 
químicos. Utilizar tecnologias que visem maximizar as exportações dentro do rigor do mercado exportador pode alavancar as exportações.

O manejo pós-colheita de doenças em mamão é baseado principalmente na utilização de fungicidas (6), incluindo a antracnose. No entanto, devido aos riscos à saúde humana, ao meio ambiente, somado ainda à perda de eficiência de alguns produtos, em razão do surgimento de populações resistentes, a cadeia produtora, fortemente estimulada pelo mercado consumidor, tem demandado a busca de outros métodos de controle de doenças. Mas, encontrar alternativas seguras, eficazes e comercialmente viáveis para reduzir as perdas pós-colheita, tem sido um desafio.

O controle biológico pela aplicação de microrganismos antagonistas é uma dessas estratégias que visa substituir e/ou minimizar o uso de defensivos. Dentre os estudos utilizando agentes de biocontrole de doenças pós-colheita em mamão (28) e outras culturas, as leveduras (19), fungos (30) e bactérias (21) vêm sido reportadas e com resultados promissores.

Bactérias associam-se em superfícies pela formação de biofilmes, que é definido como uma matriz de população microbiana aderente entre si e/ou às superfícies e interfaces (9). O biofilme pode atuar como barreiras de natureza física, química e/ou biológica à colonização de fitopatógenos. Assim, isolados bacterianos que apresentam alta capacidade de formação de biofilme, associado a outros mecanismos de biocontrole, na superfície de um fruto de mamão, poderiam contribuir eficazmente para o controle de doenças pós-colheita. Assim, a capacidade de formação do biofilme pode ser uma característica a ser considerada na seleção de antagonistas bacterianos, uma vez que poderia influenciar o sucesso do biocontrole.

Com o trabalho, buscou-se avaliar a redução da severidade da antracnose pós-colheita em frutos de mamão, pela aplicação de bactérias epifíticas do mamoeiro antagonistas a Colletrotrichum brevisporum, selecionadas quanto à produção de compostos antimicrobianos difusíveis, voláteis, quitinase, pela inibição da germinação de conídios e capacidade de formação de biofilme. Ainda, foi estimada a dosagem ótima da suspensão de antagonistas aplicada.

\section{MATERIAL E MÉTODOS}

\section{Microrganismos e sua origem.}

Bactérias provenientes de material vegetal de mamoeiros sem histórico de doenças, preservadas a $-80{ }^{\circ} \mathrm{C}$, foram empregadas nos ensaios. Nas inoculações, utilizou-se Colletotrichum brevisporum.

Foi realizado um 'screening' inicial in vitro em que as bactérias foram avaliadas quanto à capacidade de inibir o crescimento micelial de C. brevisporum pela produção de compostos antimicrobianos difusíveis e voláteis, síntese de quitinase e quanto à capacidade de inibição da germinação de conídios do patógeno (25).

No ensaio de compostos antimicrobianos difusíveis, a presença de um halo de inibição entre a bactéria e o patógeno caracterizou o antagonismo, permitindo a seleção do isolado em teste. Para produção de compostos antimicrobianos voláteis, foram selecionados os isolados que inibiram o crescimento do fungo acima de $50 \%$, em comparação ao controle. A produção de quitinase foi verificada pela presença de halo no meio de cultura, fator esse de seleção. Antagonistas que, em média, inibiram a germinação de no mínimo $80 \%$ dos conídios, foram classificados para os ensaios subseqüentes.

Antibiose entre antagonistas

Vislumbrando o emprego dos antagonistas em combinações de isolados, foi realizado um ensaio de antibiose recíproca entre 18 isolados, sendo eles os identificados pelos códigos: 628, 734, 769, 769, 777, 784, 788, 794, 801, 901, 905, 916, 917 e 924. Estes foram selecionados por apresentarem pelo menos dois mecanismos de ação contra C. brevisporum, à exceção dos isolados 761, 787, 803 e 883, que exibiram apenas um mecanismo de ação, mas que, no entanto, se destacaram por significativa inibição do crescimento in vitro do patógeno em até $95 \%$. Empregou-se o teste da dupla camada (24). A presença de halos caracterizou a incompatibilidade entre os isolados bacterianos, restringindo as combinações.

\section{Quantificação da formação de biofilme}

Os dezoito isolados utilizados no teste anterior foram avaliados quanto à capacidade de formação de biofilme em microplacas de poliestireno, de acordo com (8). As quantificações foram realizadas após 24 / 48 / 72 horas de incubação. O ensaio foi conduzido utilizandose o delineamento inteiramente casualizado, com oito repetições por isolado, e as médias comparadas pelo teste Skott-Knott (5\%). As leituras das densidades óticas obtidas foram relacionadas à adesão das células bacterianas ao poliestireno e, conseqüentemente, maior capacidade de formação de biofilme.

\section{Avaliação da redução da antracnose em discos de frutos}

Quantificou-se a redução da antracnose em discos de frutos mamoeiro tratados com agentes bacterianos. Foram estabelecidas cinco combinações de isolados, a partir de onze antagonistas selecionados nos ensaios anteriores. Às combinações deu-se a denominação de "Mix". Cada Mix foi composto por quatro isolados, de forma a equilibrar os mecanismos de biocontrole, considerando ainda os antagonistas que apresentavam ao menos dois mecanismos de ação, compatibilidade para uso combinado e destacada quantificação de biofilme.

Foram utilizados frutos do grupo Formosa, variedade 'Tainung 01', sadios e colhidos em estádio de maturação comercial 1, que foram limpos em água corrente, imersos em álcool $70 \%$ por 1 minuto, em hipoclorito de sódio $2 \%$, por 5 minutos, lavados com água esterilizada, e secos ao ar. Discos de frutos de $2 \mathrm{~cm}$ de diâmetro e $0,5 \mathrm{~cm}$ de espessura foram retirados e colocados sobre papel de filtro umedecido, em caixas tipo "gerbox". Sobre os discos, adicionaram-se $20 \mu \mathrm{L}$ de suspensão bacteriana nas concentrações $10^{6}, 10^{7}$ e $10^{8} \mathrm{UFC} \mathrm{mL}^{-1}$, e o mesmo volume de uma suspensão de conídios a $10^{6}$ conídios $\mathrm{mL}^{-1}$, concomitantemente. Após a inoculação, as caixas foram mantidas em incubadora a $25^{\circ} \mathrm{C}$, por sete dias.

Os discos foram fotografados, e a área lesionada foi mensurada por meio do software Assess 2.0 (Image analysis software for plant disease quantification). $\mathrm{O}$ ensaio foi montado no delineamento inteiramente casualizado em esquema fatorial $5 \times 3$, no qual foram cinco tratamentos, avaliados nas três concentrações diferentes, com cinco repetições por tratamento, cinco discos por repetição. O controle positivo foi composto por discos de frutos inoculados apenas com o patógeno, e o negativo, tratados com água destilada esterilizada. A comparação das médias de área lesionada foi realizada pelo teste Skott-Knott a $5 \%$ de probabilidade, com o auxílio do programa estatístico Sisvar (versão 5.6).

\section{Avaliação da redução da antracnose em frutos}

Em frutos de mamão avaliaram-se os dois "Mix" que proporcionaram os melhores resultados no ensaio anterior, quanto à capacidade de redução da doença. Dentre os tratamentos foi incluído ainda o fungicida Piraclostrobina ( $250 \mathrm{~g} / \mathrm{L})$. O ensaio foi realizado com frutos de mamão no estádio 1 de desenvolvimento, considerando a presença de ferimentos. 
Os frutos do grupo Formosa, variedade 'Tainung 01', foram provenientes de pomares sem incidência da antracnose, e cultivados em sistema orgânico de cultivo. Foram lavados em água corrente, imersos em álcool $70 \%$ por 1 minuto, seguido de imersão em hipoclorito de sódio $2 \%$, por 3 minutos, lavados com água destilada, e secos ao ar. Foram tratados pulverizando-se suspensão aquosa dos antagonistas na concentração ótima obtida no ensaio anterior $\left(10^{8}\right.$ UFC $\mathrm{mL}^{-1}$ ), em combinações de isolados, até o ponto de escorrimento. A seguir, procedeu-se à inoculação por suspensão de conídios de Colletotrichum brevisporum $\left(10^{6} \mathrm{con} \mathrm{mL}^{-1}\right)$. Os frutos sofreram uma injúria longitudinal de $3 \mathrm{~cm}$ de comprimento em sua casca e foram acondicionados em caixas plásticas de $10 \mathrm{~L}$, sobre papel de filtro umedecido, permanecendo a temperatura ambiente por sete dias. Decorrido este intervalo, a área lesionada foi mensurada nos frutos, por meio da análise de imagens, utilizando o software Assess 2.0. O ensaio foi montado em delineamento inteiramente casualizado com cinco repetições, cada repetição composta por dois frutos. O controle positivo foi composto por frutos inoculados com o patógeno e sem tratamento, e negativo com frutos tratados apenas com água destilada. A comparação das médias de área lesionada foi realizada pelo teste Tukey a $5 \%$ de probabilidade, com o auxílio do programa estatístico Sisvar (versão 5.6). O ensaio foi repetido duas vezes.

\section{RESULTADOS}

\section{Seleção de bactérias epifíticas antagonistas a Colletotrichum brevisporum.}

Um total de 224 isolados bacterianos epifíticos, isolados de tecidos de mamoeiro, envolvendo folhas, frutos e sementes, foram avaliados quanto à capacidade de sintetizar compostos antimicrobianos difusíveis e voláteis, quitinase e inibição da germinação de conídios de Colletotrichum brevisporum. Noventa e dois antagonistas foram selecionados, dentre estes, setenta e seis apresentaram ao menos um dos mecanismos de ação supracitados efetivos contra o patógeno em ensaios in vitro.
A produção de compostos voláteis foi o destaque dentre os mecanismos de biocontrole avaliados, em que 47 isolados apresentaram níveis de inibição do micélio do patógeno a partir de $50 \%$, chegando a $92 \%$. Seguiu-se a produção de quitinase com 17 isolados.

A produção de compostos antimicrobianos difusíveis de forma isolada, inibindo o crescimento de C. brevisporum, foi constatada para dois isolados. Oito bactérias foram eficazes na supressão da germinação de conídios do patógeno, com valores acima de $80 \%$. Porém, há que se destacar que uma baixa germinação do conídios foi observada em todos os isolados avaliados.

Dezoito isolados, ou seja, 8,0 \% do total avaliado apresentaram mais de um mecanismo de ação, o que é desejável na seleção de antagonistas, já que amplia as chances de sucesso no biocontrole. Dentre estes, quatro exibiram três mecanismos de ação e um deles, todos os mecanismos.

Verificou-se uma alta inibição in vitro do crescimento de Colletotrichum brevisporum por meio da ação de compostos voláteis. A produção destes compostos foi constatada em $68,5 \%$ dos isolados selecionados, quando considerado unicamente.

\section{Antibiose entre antagonistas}

Visando averiguar a compatibilidade dos antagonistas, a fim de utilizá-los de forma combinada, procedeu-se à antibiose recíproca. Foram avaliados 14 antagonistas que apresentavam pelos menos dois mecanismos de inibição do patógeno, e quatro com apenas um mecanismo.

Verificou-se que o isolado 924 inibiu as bactérias 734, 769, 784 e 788, que apresentaram três mecanismos de ação. Apesar disso, o mesmo foi selecionado para a etapa posterior do trabalho por inibir o patógeno por meio da produção de compostos voláteis e quitinase, tomando-se o cuidado de separá-lo dos antagonistas inibidos nas combinações.

Adicionalmente ao fato de possuírem apenas um mecanismo de inibição a C. brevisporum, os isolados 761, 787 e 803 foram incompatíveis com o isolado 901, que apresentou todos os mecanismos de ação. Esse resultado fez com que os três antagonistas fossem excluídos do ensaio em discos de frutos.

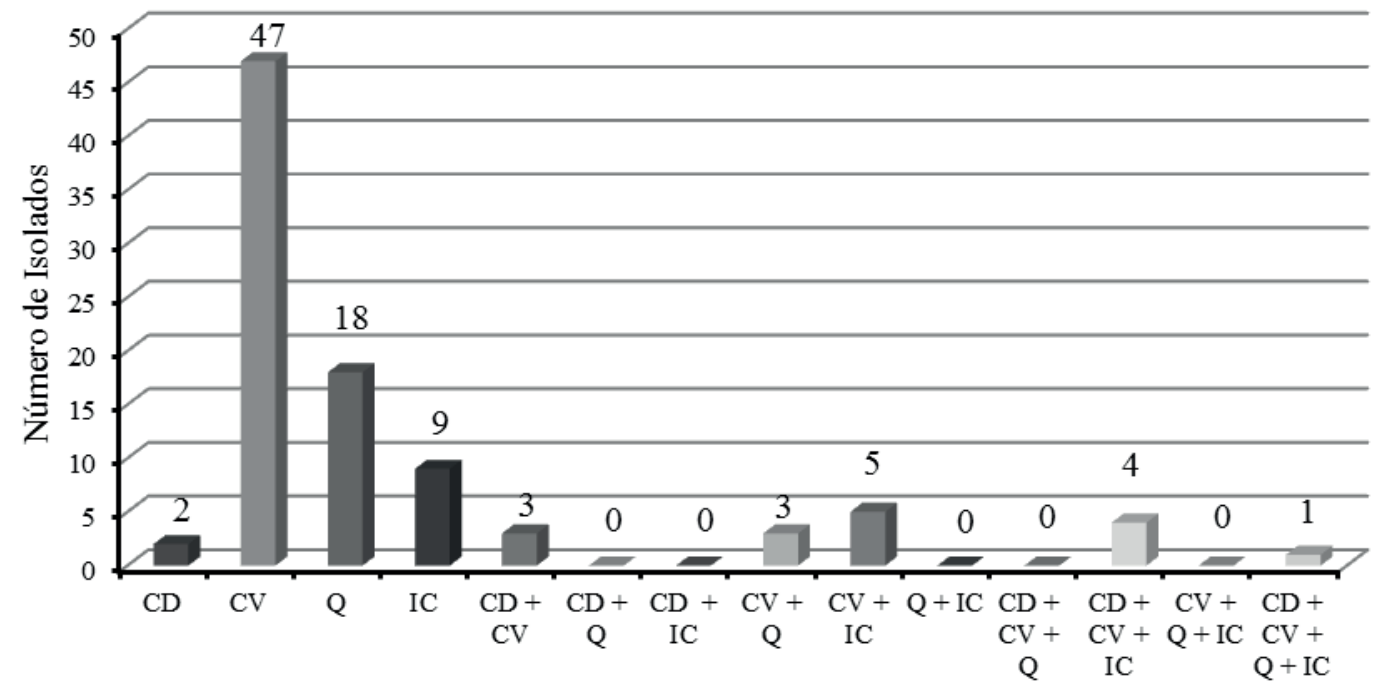

Mecanismos de Ação

Figura 1. Disposição dos mecanismos de ação presentes em antagonistas bacterianos epifíticos de mamoeiro. (CD - compostos difusíveis, CV compostos voláteis, Q - quitinase, IC - Inibição da germinação de conídios). 
Tabela 1. Bactérias epifíticas de mamoeiro, selecionados quanto à produção de compostos antimicrobianos difusíveis e voláteis, quitinase e inibição da germinação de conídios de Colletotricum brevisporum.

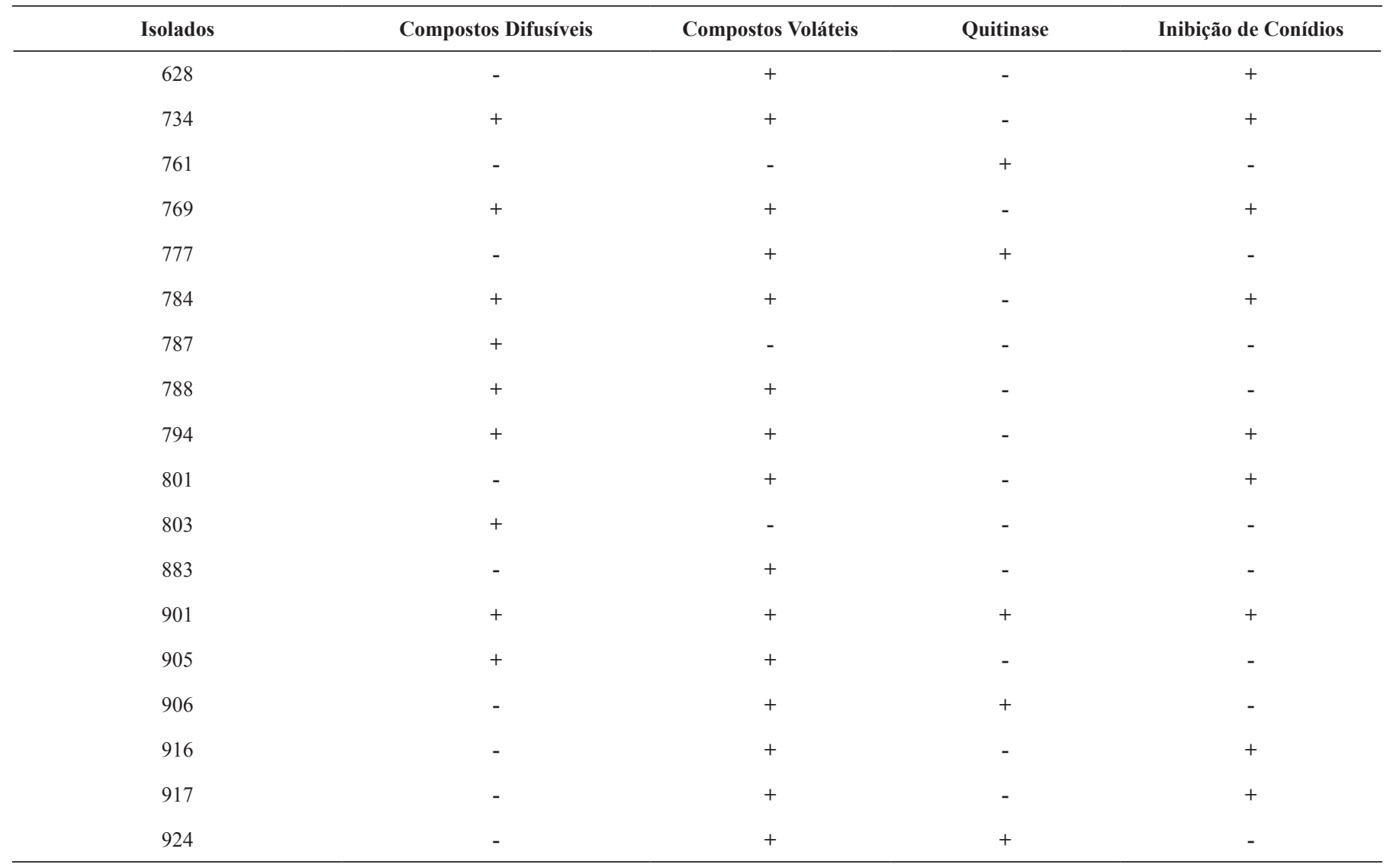

(+) Positivo para o mecanismo avaliado; (-) Negativo para o mecanismo avaliado

Tabela 2. Compatibilidade entre bactérias selecionadas como antagonistas a Colletotrichum brevisporum.

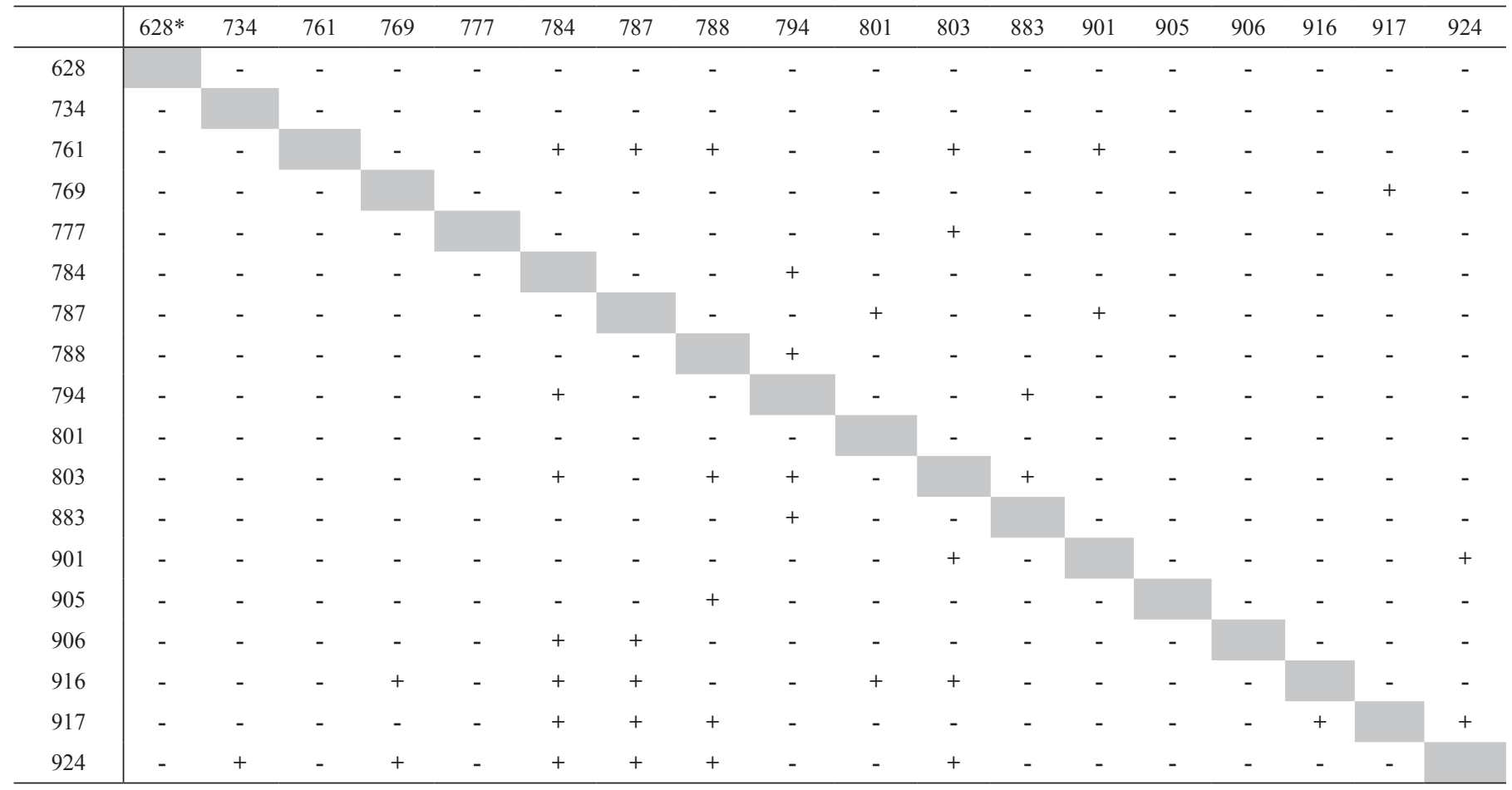

*(-) ausência de inibição; (+) inibição. Coluna à esquerda, inibidores; linha superior, inibidos. 
Avaliação in vitro da capacidade de formação de biofilme das bactérias epífitas

Para todos os antagonistas em estudo constatou-se a adesão das células em poliestireno. Após 48 horas de incubação, a formação de biofilme foi crescente, exceto para o isolado 628. As bactérias 777, 784 e 794 apresentaram maior adesão de células nos poços, e a produção do biofilme aumentou progressivamente.Os resultados com $72 \mathrm{~h}$ de incubação sugerem que ocorreu maior agregação celular, e que a produção de biofilme tende a aumentar com o esgotamento dos nutrientes do meio. Curiosamente, os isolados 734, 761, 801, 803, 883, 905, 906, 917 e 924, após 24 horas, apresentaram baixos valores de produção do biofilme. No entanto, após 48 horas, a produção aumentou. O isolado 628 foi único que indicou possível desagregação do biofilme após 48 horas.Observou-se a formação de cinco grupos de antagonistas, quanto à produção de biofilme, quando da avaliação às 72 h. No grupo com maiores níveis de produção de biofilme, três isolados, imediatamente seguido pelo segundo grupo com seis bactérias. E finalmente o terceiro grupo com seis antagonistas. Com base nesse resultado, na presença de mais de um mecanismo de ação por antagonista e na compatibilidade entre isolados, selecionaram-se para os ensaios em discos de frutos os isolados: 734, 769, 777, 784, 788, 794, 901, 905, 906, 916 e 924.Neste ensaio, também foram obtidos maiores valores de adesão celular no tempo de 72 horas de incubação sugerindo que não houve desagregação das células do biofilme com o esgotamento de nutrientes, exceto para o isolados 628 e 801.
Avaliação da redução da antracnose em discos de frutos

Os Mix bacterianos foram combinados baseados nos diferentes mecanismos de ação inerentes a cada antagonista, cujos isolados foram dispostos de forma a equilibrar as combinações, além da compatibilidade entre isolados e capacidade de formação de biofilme. Foram estabelecidos cinco Mix, mais dois controles, tratamentos estes avaliados em discos de frutos.

Após sete dias da montagem do ensaio, os discos foram avaliados quanto à área lesionada. Os Mix 3 e 5 apresentaram maior eficiência reduzindo a doença em entre $80 \%$ e $90 \%$, nas concentrações $10^{7}$ e $10^{8} \mathrm{UFC} \mathrm{mL}^{-1}$, respectivamente, quando comparado ao controle com apenas o patógeno. Nas mesmas concentrações, o Mix 4 também reduziu de forma significativa a doença, porém em nível inferior ao dos combinados anteriores. O Mix 1 proporcionou resultados significativos apenas na concentração $10^{8} \mathrm{UFC} \mathrm{mL}^{-1}$, enquanto que o Mix 2 não diferiu do controle.

Resultados semelhantes foram encontrados quando foi aplicada a concentração de $10^{6} \mathrm{UFC} \mathrm{mL}^{-1}$, considerando os tratamentos entre si e o controle. Porém, quando se avaliou a concentração dentro de cada tratamento o Mix 3 foi o de melhor desempenho, sem variar os níveis de controle da doença. Os resultados desse estudo deram subsídio para a seleção dos "Mix" 3 e 5 na concentração $10^{8}$ UFC $\mathrm{mL}^{-1}$, que foram empregados no ensaio posterior, para verificar a redução da antracnose em frutos de mamão.

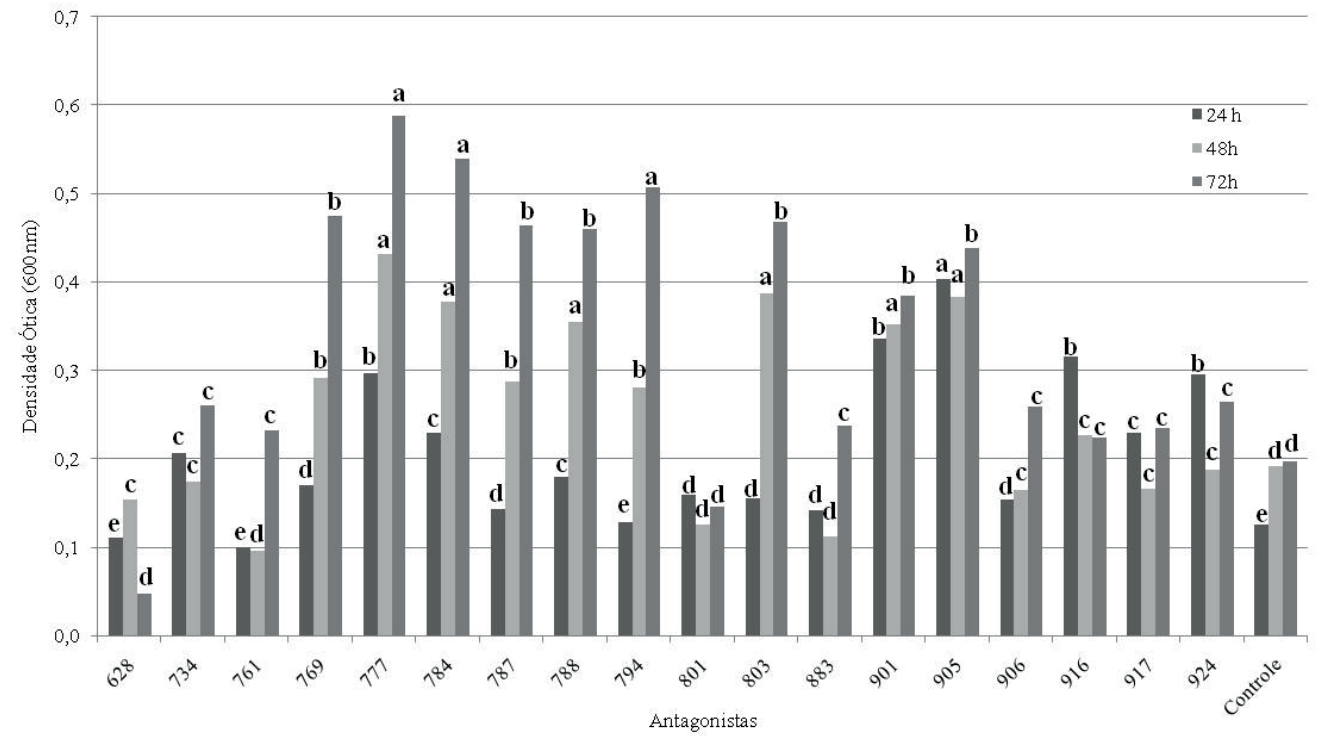

Figura 2. Quantificação da formação de biofilme bacteriano por bactérias epifíticas antagonistas a Colletotrichum brevisporum em diferentes intervalos. *Tratamentos seguidos da mesma letra em barras da mesma cor não apresentam diferença significativa pelo Teste de Skott-Knott a 5 \%

Tabela 3. Composição dos "Mix" bacterianos aplicados em discos de frutos de mamão para controle da antracnose.

\begin{tabular}{lllllll}
\hline Mix 1 & 901 & 784 & 777 & 916 & 906 & 905 \\
Mix 2 & 901 & 734 & 924 & 916 \\
Mix 3 & 901 & 794 & 906 & 905 \\
Mix 4 & 901 & 769 & 916 & 788 \\
\hline
\end{tabular}


Tabela 4. Porcentagem área lesionada por antracnose em discos de frutos de mamão tratados com bactérias epifíticas antagonistas a Colletotrichum brevisporum.

\begin{tabular}{|c|c|c|c|}
\hline \multirow{2}{*}{ Tratamentos } & \multicolumn{3}{|c|}{ Concentrações (UFC mL mL $\left.^{-1}\right)$} \\
\hline & $10^{8}$ & $10^{7}$ & $10^{6}$ \\
\hline Mix 1 & $25,22 \mathrm{Aa}^{*}$ & $99,07 \mathrm{Cb}$ & $99,30 \mathrm{Cb}$ \\
\hline Mix 2 & $93,23 \mathrm{Ca}$ & $87,65 \mathrm{Ca}$ & $99,73 \mathrm{Ca}$ \\
\hline Mix 3 & $10,88 \mathrm{Aa}$ & $18,56 \mathrm{Aa}$ & $17,80 \mathrm{Aa}$ \\
\hline Mix 4 & $64,81 \mathrm{Ba}$ & $61,11 \mathrm{Ba}$ & $64,73 \mathrm{Ba}$ \\
\hline Mix 5 & $9,22 \mathrm{Aa}$ & $1,92 \mathrm{Aa}$ & $40,00 \mathrm{Ab}$ \\
\hline Controle & $99,27 \mathrm{Ca}^{*}$ & $99,25 \mathrm{Ca}$ & $99,76 \mathrm{Ca}$ \\
\hline
\end{tabular}

*Médias seguidas pela mesma letra maiúscula na coluna e minúscula na linha, não diferem significativamente entre si pelo Teste de Tukey a 5 \%.

\section{Avaliação da redução da antracnose em frutos inteiros}

Tanto nos ensaios em discos de frutos como em frutos, a conciliação de diferentes mecanismos de ação acionados por cada uma das bactérias epifíticas, expressados de forma conjunta pela associação na superfície do fruto em biofilme, pode ter contribuído para a redução da antracnose.

Após sete dias de incubação a $25^{\circ} \mathrm{C}$ para frutos da variedade do grupo Formosa verificou-se que os "Mix" dos antagonistas reduziram significativamente a doença. Embora não tenham diferido do tratamento com aplicação de fungicida Piraclostrobina ( $250 \mathrm{~g} / \mathrm{L})$, que é o método mais utilizado no controle da antracnose em mamoeiro, que exibiu controle de 97,92 \% da doença, nos tratamentos cujos "Mix 3" e "Mix 5 " foram utilizados, verificou-se uma eficácia de redução da doença de, respectivamente, $98,5 \%$ e $98,77 \%$.

\section{DISCUSSÃO}

O biocontrole em pós-colheita por agentes bacterianos, no "frutoplano", é uma linha de estudo muito presente na literatura científica. A seleção de bactérias antagonistas como agentes de biocontrole da antracnose, por meio de ensaios in vitro, aliados à quantificação da produção de biofilme proporcionou significativos resultados quanto à redução da doença em frutos no presente trabalho.

Verificou-se uma alta inibição in vitro do crescimento de Colletotrichum brevisporum por meio da ação de compostos voláteis. A produção destes compostos foi constatada em $92 \%$ dos isolados selecionados, quando considerado unicamente. Uma possível explicação para supressão do crescimento fúngico por meio da produção dos compostos voláteis, se dá em decorrência da diversidade de metabolitos secundários como itaurinas, surfactina, dentre outros comumente produzidos por agentes de biocontrole (4).

Isolados de Bacillus spp. selecionados como produtores de compostos antimicrobianos voláteis foram relatados inibindo o crescimento micelial de Phyllosticta citricarpa, agente causal da mancha preta dos citros, em até $76 \%$ in vitro, e $86 \%$ dos sintomas nos frutos in vivo (FUJIMOTO; KUPPER, 2016). Em outro estudo, Zheng et al. (32) constataram que compostos voláteis de B. pumilus e $B$. thuringiensis reduziram as infecções por antracnose em mangas em

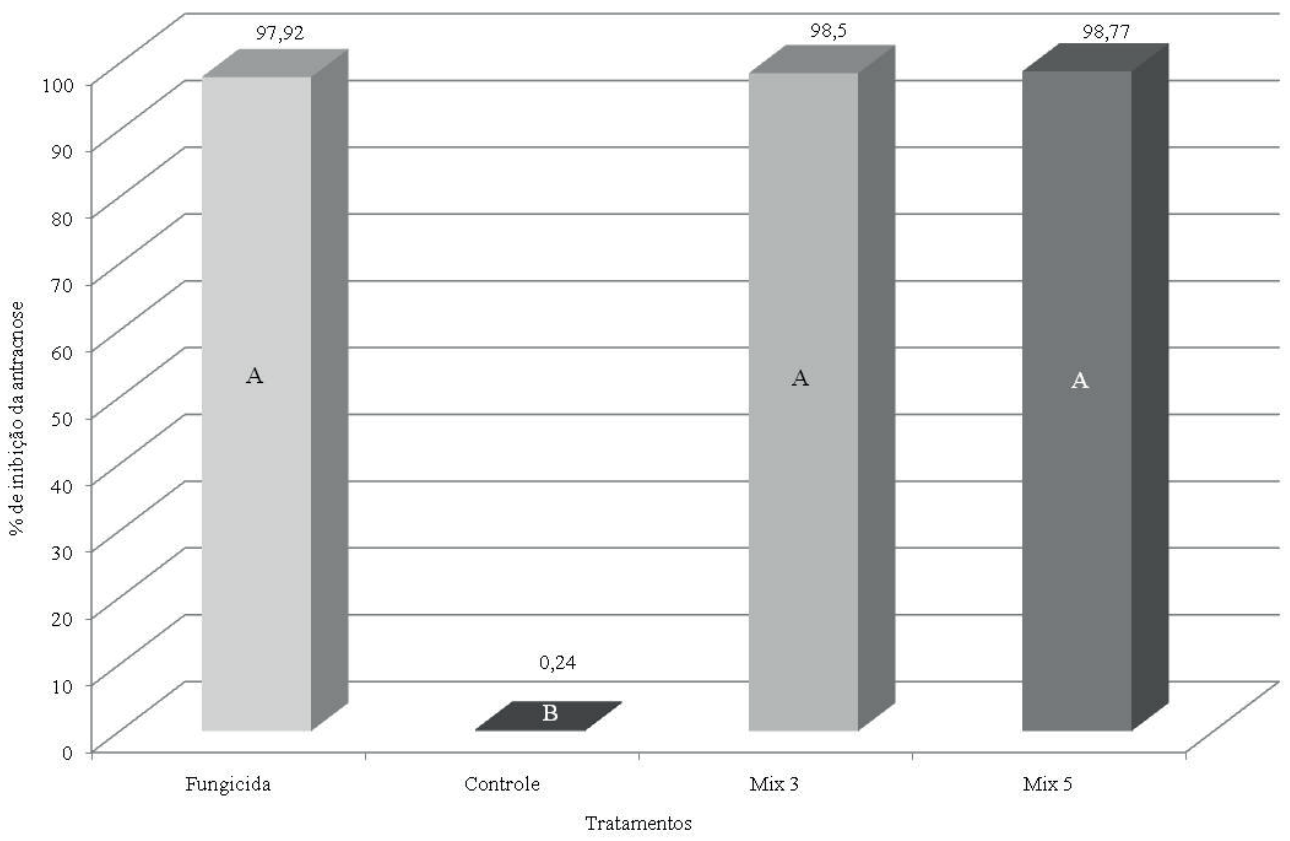

Figura 3. Área lesionada por Colletotrichum brevisporum em frutos de mamão do grupo Formosa, tratados com bactérias antagonistas. Tratamentos seguidos da mesma letra não diferem significativamente pelo teste Tukey $5 \%$. 
$88,5 \%$. É válido ressaltar a importância desses compostos, uma vez que a inibição do patógeno pode ocorrer em curtas ou longas distâncias.

As quitinases, detectadas em alguns isolados, são enzimas hidrolíticas que podem ser produzidas por agentes de biocontrole, com a finalidade de degradar polímeros de quitina, que são constituintes da parede celular de fungos e insetos (11). Embora as quitinases não sejam consideradas essenciais para a maioria das bactérias, sua produção lhes garante uma vantagem adaptativa, já que a quitina degradada pode ser utilizada como fonte de energia na ausência de outras fontes de carbono. Em se tratando de antagonistas a fungos fitopatogênicos, como Colletotrichum spp., a produção de quitinases pode desempenhar um papel de inibição, pois a parede celular é essencial para a sobrevivência dos ascomicetos, e são constituídas principalmente por quitina (14).

Quanto à produção de compostos antimicrobianos difusíveis, esse é um atributo vantajoso em um agente de biocontrole, pois estas substâncias que podem ser antibióticos como fengicinas e itaurinas, por exemplo, ou enzimas que podem difundir-se de forma acelerada no tecido alvo, tornando dispensável o contato direto entre o fitopatógeno e o antagonista (12). Kim et al. (16) verificaram o controle da antracnose em até $50 \%$ por Bacillus subtilis CMB32, por meio da produção de antibióticos como itaurina A, fengicina e surfactina A.

A baixa germinação do conídios do patógeno foi observada para todos os isolados avaliados. A presença deste mecanismo de ação em um antagonista destaca-se, quando a ocorrência da doença está diretamente ligada à germinação dos conídios do patógeno no filoplano, como é o caso da antracnose. É sabido que Colletotrichum spp. geralmente infecta o hospedeiro ainda no campo, e antagonistas que apresentam tal característica podem ser utilizados no controle biológico, a fim de retardar ou até inibir o desenvolvimento do patógeno nessa fase.

Embora 47 antagonistas houvessem sido selecionados pela produção de compostos antimicrobianos voláteis, outros 27 isolados inibiram o crescimento fúngico frente ao controle, porém abaixo do nível mínimo estabelecido para a seleção. Dentre estas 74 bactérias, ao todo, observou-se que para 64 houve uma relação direta com a porcentagem de inibição da germinação de conídios do C. brevisporum (dados não mostrados). Arrebola, Sivakumar e Korsten (5) por meio de observações microscópicas de Penicillium crustosum, expostos a compostos voláteis de Bacillus subtilis e B. amyloliquefaciens, observaram anormalidades morfológicas nos conídios do fungo, como a dilatação de hifas. Embora tal estudo não tenha sido realizado nesse trabalho, aventa-se a possibilidade do fato descrito ter ocorrido para explicar o resultado obtido. Outros trabalhos tratando de relatos nessa mesma linha podem ser encontrados na literatura.

É desejável em um antagonista que ele atue por meio de mais de um mecanismo contra fitopatógenos (26). Porém, obter um isolado com tais características não é tarefa fácil, o que faz com o emprego de isolados combinados seja uma alternativa lógica e factível. Apesar dos antagonistas em teste apresentarem, na maioria das vezes, características múltiplas de inibição microbiana, o que gerou incompatibilidade entre os mesmos, em alguns casos, foi possível obter um número considerável de combinações de isolados.

Conhecer e explorar a diversidade de mecanismos inerentes a um ou a um grupo de agentes de biocontroles aumentará a eficácia de sua atuação, na redução de uma fitomoléstia (3). A ampliação do espectro da atividade microbiana resultando no controle de várias doenças, a formação de uma comunidade antagonística mais estável que possa excluir outros microrganismos, dentre eles, patógenos, e o aumento da eficiência do biocontrole são algumas das características elencáveis quando se aplicam antagonistas combinados (26).
Outro ponto a ser discutido trata da origem dos isolados, todos obtidos de plantas de mamoeiro, sem histórico da aplicação de defensivos e sem sintomas de antracnose. Utilizar agentes de biocontrole oriundos do próprio ambiente nativo, pode ser uma escolha acertada no controle de doenças pós-colheita, pois além de ser uma excelente fonte de ocorrência natural de antagonistas, são bem adaptados à superfície alvo. Vantagens do emprego de antagonistas nativos, isolados do mesmo habitat em que são eficazes para o biocontrole, já foram levantadas por (2).

A associação por biofilme é uma estratégia comum de crescimento bacteriano em superfícies. De acordo com os resultados quanto a formação e produção de biofilme bacteriano, observou-se uma possível relação entre a formação do biofilme com a produção dos compostos microbianos. Ou seja, os compostos produzidos pelas bactérias agiram como sinalizadores químicos indutores à agregação em biofilme, uma vez que os isolados foram utilizados em "mix", e a comunicação intercelular entre bactérias geralmente ocorre pela difusão de produtos bacterianos entre as células.

A emissão de sinais químicos pelas bactérias é conhecida como auto-indutores, por meio de um processo denominado de quorumsensing. Tal mecanismo permite que as bactérias captem a densidade populacional local e encadeiem a expressão gênica (10).

No caso de doenças causadas por patógenos que possuam estágio epifítico em seu ciclo de vida, como a antracnose, populações microbianas podem afetar o estabelecimento das interações plantapatógeno antes da infecção. Considerando que os biofilmes podem se desenvolver em diversas superfícies, em ambientes onde existem células viáveis, pode-se dizer que a existência de um biofilme bacteriano, na superfície de um fruto, contribuiu para formação uma barreira biológica à colonização de Colletotrichum brevisporum.

Neste ensaio, também foram obtidos maiores valores de adesão celular no tempo de 72 horas de incubação sugerindo que não houve desagregação das células do biofilme com o esgotamento de nutrientes, exceto para os isolados 628 e 801. Diversos mecanismos favorecem a desagregação dos biofilmes, e como consequiência, as células são dispersas em sentidos opostos, o que é vantajoso de certa forma, pois permite a colonização de outros nichos com condições mais favoráveis de crescimento (29).

Tanto nos ensaios em discos de frutos como em frutos, a conciliação de diferentes mecanismos de ação acionados por cada uma das bactérias epifíticas, expressados de forma conjunta pela associação na superfície do fruto em biofilme, pode ter contribuído para a redução da antracnose.

Pôde-se observar que além do controle do patógeno, os discos tratados com os "Mix" 3 e 5 mantiveram-se consistentes, de forma semelhante aos discos do controle negativo, sugerindo que a aplicação dos antagonistas poderia retardar a maturação dos frutos, possivelmente pela ativação de genes relacionados ao amadurecimento (28).

A interação entre os tratamentos e as concentrações utilizadas foi significativa, evidenciando que a concentração da suspensão dos antagonistas, influenciou na eficácia dos "Mix" no controle da antracnose. Os menores níveis de controle na concentração $10^{6}$ UFC $\mathrm{mL}^{-1}$ podem ter ocorrido em virtude da equivalência entre as populações máximas dos antagonistas e do patógeno (31).

Notadamente, as combinações bacterianas aplicadas proporcionaram um efeito protetivo nos ferimentos dos frutos. Estudando leveduras para o controle de Penicillium digitatum em citros, (1) inferiram que uma vez estabelecidos nos ferimentos dos frutos, os microrganismos utilizam todos os nutrientes liberados a partir de ferimentos, inibindo assim o estímulo à germinação dos esporos fúngicos. Ainda, segundo 
(16), a eficácia de agentes de biocontrole depende de sua capacidade de colonizar fontes de alimentos nas plantas, sem danificar as células. Considerando estes fatores, e frente aos resultados obtidos nos ensaios, a aplicação dos antagonistas concomitante ao C. brevisporum pode ter favorecido a eficiência do biocontrole. Não se descartam as hipóteses quanto a efeitos preventivos e curativos, mas ensaios envolvendo a aplicação das bactérias em intervalos anteriores e posteriores à inoculação devem ser conduzidos para comprovar essas possibilidades.

Faz-se desejável o uso de agentes de biocontrole combinados devido aos benefícios que podem ser exibidos como: adaptação aos estresses abióticos e bióticos, melhor desempenho na colonização do tecido alvo da planta, proteção contra agentes patogênicos, além da supressão de mecanismos envolvidos no desenvolvimento do patógeno. Raupach e Kloepper (22) averiguaram a eficiência da utilização de isolados combinados que exibiam distintos mecanismos de ação, como antibiose por produção de compostos antimicrobianos difusíveis e quitinase, e maior supressão de fitopatógenos quando antagonistas foram utilizados de forma combinada.

Um significativo número de trabalhos tem relatado o biocontrole de fitopatógenos com o uso de bactérias (27). Contudo, são escassos os relatos da quantificação de biofilme sendo utilizado como critério de seleção de antagonistas, tampouco no biocontrole em pós-colheita.

Os biofilmes são uma amostra da natureza agregada das populações microbianas nas superfícies das plantas. A agregação espacial tem implicações significativas para interações microbianas específicas ou interespecíficas, como, antibiose, predação e competição (18).

De acordo com os resultados obtidos, a capacidade de formação do biofilme por antagonistas desempenha papel importante na prevenção de doenças na pós-colheita. No entanto, isoladamente, não é suficiente para garantir o sucesso do biocontrole. Há que se levarem em conta que as bactérias avaliadas produziam compostos antimicrobianos difusíveis e voláteis, além de quitinases. Há que se confirmar a importância individual de cada característica, correlacionando com a capacidade ou não de formação de biofilme para cada isolado (7).

Vários relatos suportam que agentes de biocontrole podem reduzir as perdas por patógenos em frutos por meio da indução de resistência sistêmica, em pós-colheita (23). Não foram realizados testes envolvendo tal fenômeno biológico, mas é uma hipótese não descartada e que poderia ser investigada, para explicar os excelentes níveis de controle obtidos nos ensaios. Da mesma forma, a competição por nutrientes ou sítios de infecção é outra questão que pode ser estudada para elucidação do envolvimento desse mecanismo de ação por parte dos antagonistas avaliados.

É sabido que, atualmente, no Brasil, o controle da antracnose, na pós colheita, é realizada em sua grande maioria por meio da aplicação de defensivos agrícolas, em virtude da eficiência do produto. No entanto, sabem-se também dos impactos ambientais e na saúde humana, assim como o surgimento estipes resistentes dos patógenos, provocados pelo uso indiscriminado dos agroquímicos. Neste estudo pôde-se verificar que o biocontrole bacteriano é uma método viável e eficaz para o controle da antracnose em pós-colheita, uma vez não houve diferença significativa entre os tratamentos MIX 3 e 5, quando comparados ao fungicida Piraclostrobina. Ressalta-se que em etapas posteriores sejam realizados novos testes em que sejam analisados tempos distintos de aplicação dos mesmos nos frutos, já que no presente trabalho, antagonistas e o patógeno foram aplicados concomitantemente.

Para ampliar e consolidar o emprego do biocontrole de fitopatógenos há que se promoverem estratégias, baseadas na integração de diferentes métodos de controle, de modo a se obter um efeito aditivo ou sinergístico. Assim, a compatibilidade entre microrganismos e fungicida é uma opção também a ser estudada, vislumbrando seu emprego combinado, em um contexto de manejo integrado da antracnose em pós-colheita.

Pôde-se concluir mediante os resultados obtidos que isolados bacterianos combinados, selecionados com base na síntese de compostos antimicrobianos, quitinase, inibição da germinação de conídios e na quantificação da produção de biofilme, reduzem a severidade da antracnose em frutos de mamão, quando aplicados em pós-colheita, em nível similar ao tratamento com fungicida, podendo ser aplicados em alternância ou em substituição ao tratamento químico, para o controle de Colletotrichum brevisporum.

\section{AGRADECIMENTOS}

Os autores agradecem a Coordenação de Aperfeiçoamento de pessoal de Nível Superior (CAPES), e a Embrapa Mandioca e Fruticultura pelo apoio financeiro a este trabalho.

\section{REFERÊNCIAS}

1. ABRAHAM, A. O.; LAING, M. D.; BOWER, J. P. Isolation and in vivo screening of yeast and Bacillus antagonists for the control of Penicillium digitatum of citrus fruit. Biological Control, Pietermaritzburg, v. 53, n. 1, p. 32-38, 2010. doi: 10.1016/j.biocontrol.2009.12.009

2. ALVINDIA, D. G.; NATSUAKI, K. T. Evaluation of fungal epiphytes isolated from banana fruit surfaces for biocontrol of banana crown rot disease. Crop Protection, Nueva Ecija, v. 27, n. 8, p. 1200-1207, 2008. doi: 10.1016/j. cropro.2008.02.007

3. ALVINDIA, D. G.; NATSUAKI, K. T. Biocontrol activities of Bacillus amyloliquefaciens DGA14 isolated from banana fruit surface against banana crown rot-causing pathogens. Crop Protection, Nueva Ecija, v. 28, n. 3, p. 236-242, 2009. doi: 10.1016/j.cropro.2008.10.011

4. ANDRADE, C. J.; ANDRADE, L. M.; BUTION, M. L.; DOLDER, M. A. H.; BARROS, F. F. C.; PASTORE, G. M. Optimizing alternative substrate for simultaneous production of surfactin and 2,3-butanediol by Bacillus subtilis LB5a. Biocatalysis and Agricultural Biotechnology, São Paulo,v. 6, p. 209-218, 2016. doi: 10.1016/j.bcab.2016.04.004

5. ARREBOLA, E.; SIVAKUMAR, D.; KORSTEN, L. Effect of volatile compounds produced by Bacillus strains on postharvest decay in citrus. Biological Control, Pretória, v. 53, n. 1, p. 122-128, 2010. doi: 10.1016/j. biocontrol.2009.11.010

6. BAUTISTA-BANÕS, S.; SIVAKUMAR, D.; BELLO-PÉREZ, A.; VILLANUEVA-ARCE, R.; HERNÁNDEZ-LÓPEZ, M. A review of the management alternatives for controlling fungi on papaya fruit during the postharvest supply chain. Crop Protection, San Isidro Yautepec Morelos, v. 49, p. 8-20, 2013. doi: 10.1016/j.cropro.2013.02.011

7. CHEN, Y.; YAN, F.; CHAI, Y.; LIU, H.; KOLTER, R.; LOSICK, R.; GUO, J. H. Biocontrol of tomato wilt disease by Bacillus subtilis isolates from natural environments depends on conserved genes mediating biofilm formation. Environmental Microbiology, Nanjing, v. 15, n. 3, p. 848-864, 2013. doi: 10.1111/j.1462-2920.2012.02860.x

8. CONWAY, B. A. D.; VENU, V.; SPEERT, D. P. Biofilm formation and acyl homoserine lactone production in the Burkholderia cepacia complex. Journal of Bacteriology, British Columbia v. 184, n. 20, p. 5678-5685, 2002. doi: 10.1128 / JB.184.20.5678-5685.2002

9. COSTERTON, J. W.; LEWANDOWSKI, Z.; CALDWELL, D. E.; KORBER, D. R.; LAPPIN-SCOTT, H. M. Microbial biofilms. Annual Review of Microbiology, Saskatoon, v. 49, p. 711-745, 1995. doi: 10.1146/annurev. mi.49.100195.003431

10. DAVIES, D. G.; PARSEK, M. R., PEARSON, J. P.; IGLEWSKI, B. H., COSTERTON, J. W.; GREENBERG, E. P. The involvement of cell-to-cell signals in the development of a bacterial biofilm. Science, Bozeman, v. 280, n. 5361 , p. $295-298$, 1998. doi: $10.1126 /$ science. 280.5361 .295

11. FLEURI, L. F.; SATO, H. H. $\beta-1,3$ glucanases e quitinases: aplicação na lise de leveduras e inibição de fungos. Ciência e Agrotecnologia, v. Campinas, 32, n. 4, p. 1224-1231, 2008. doi: 10.1590/S1413-70542008000400029

12. FUJIMOTO, A.; KUPPER, K. C. production of antifungal compounds and 
hydrolytic enzymes by Bacillus spp. as mechanisms of action against Phyllosticta citricarpa. IOSR Journal Of Agriculture And Veterinary Science, Jaboticabal, v. 9, n. 11, p. 19-27, 2016. doi: 10.9790/2380-0911021927

13. GOUDJAL, Y.; TOUMATIA, O.; YEKKOUR, A.; SABAOU, N. MATHIEU, F.; ZITOUNI, A. Biocontrol of Rhizoctonia solani damping-off and promotion of tomato plant growth by endophytic actinomycetes isolated from native plants of Algerian Sahara. Microbiological Research, Kouba, v. 169 n. 1, p. 59-65, 2014. doi: 10.1016/j.micres.2013.06.014

14. HOWARD, M. B.; EKBORG, N. A., WEINER, R. M., HUTCHESON, S. W. Detection and characterization of chitinases and other chitin-modifying enzymes. Journal of Industrial Microbiology and Biotechnology, College Park, v. 30, n. 11, p. 627-635, 2003. doi: 10.1007/s10295-003-0096-3

15. INCAPER. Polos de fruticultura. Disponível em: $<$ https://incaper.es.gov.br/ fruticultura-mamao $>$. Acesso em: 23 julho 2018.

16. JANISIEWICZ, W. J.; PETERSON, D. L.; BORS, R. Control of storage rots of apples with Sporobolomyces roseus. Plant Disease, Kearneysville v. 78, n. 5, 466-470, 1993. doi: 10.1094/PD-78-0466

17. KIM, P. I; RYU, J.; KIM, Y. H.; CHI, Y. T. Production of biosurfactant lipopeptides iturin A, fengycin, and surfactin A from Bacillus subtilis CMB32 for control of Colletotrichum gloeosporioides. Journal of Microbiology and Biotechnology, Seul, v. 20, n. 1, p. 138-145, 2010. doi: 10.4014/ jmb.0905.05007

18. KINKEL, L. L.; NEWTON, M. R.; LEONARD, K. J. Resource aggregation in the phyllosphere: implications for microbial dynamics across spatial scales. In: Lindow, S. E.; Hecht-Poinar, E. I.; Elliott, V. J. (Eds.). Phyllosphere Microbiology. The American Phytopathological Society, St. Paul, p. 317-340, 2002. doi:20033112512

19. LIMA, J. R.; VIANA, F. M. P.; LIMA, F. A.; LIMA, J. S.; PIENIZ, V.; GONÇALVES, L. R. B. Biocontrole da antracnose pós-colheita do mamão com levedura killer. Boletim de Pesquisa e Desenvolvimento 59 / Embrapa Agroindústria Tropical, Fortaleza-CE, 2012. 20p.

20. LIU, F.; WEIR, B. S.; DAMM, U.; CROUS, P. W.; WANG, Y.; LIU, B.; CAI, L. Unravelling Colletotrichum species associated with Camellia: employing ApMat and GS loci to resolve species in the C. gloeosporioides complex. Persoonia - Molecular Phylogeny and Evolution of Fungi, Beijing, v. 35, p. 63-86, 2015. doi: 10.3767/003158515X687597

21. OSMAN, S. M.; SIVAKUMAR, D.; KORSTEN, L. Effect of biocontrol agent Bacillus amyloliquefaciens and 1-methyl cyclopropene on the control of postharvest diseases and maintenance of fruit quality. Crop Protection, Ed Duiem, v. 30, n. 2, p. 173-178, 2011. doi: 10.1016/j.cropro.2010.09.014

22. RAUPACH, G. S.; KLOEPPER, J. W. Mixtures of plant growth-promoting rhizobacteria enhance biological control of multiple cucumber pathogens. Phytopathology, Auburn, v. 88, n. 11, p. 1158-1164, 1998. doi: doi. org/10.1094/PHYTO.1998.88.11.1158
23. ROMANAZZI, G.; SANZANI, S. M.; BI, Y.; TIAN, S.; MARTÍNEZ, P G.; ALKAN, N. Induced resistance to control postharvest decay of fruit and vegetables. Postharvest Biology and Technology, Ancona, v. 122, p. 82-94, 2016. doi: 10.1016/j.postharvbio.2016.08.003

24. ROMEIRO, R. S. Métodos em Bacteriologia de Plantas. Viçosa: UFV, 2001. $279 \mathrm{p}$.

25. SANTOS, L. A. L. Bactérias epifíticas como agentes de biocontrole da antracnose do mamoeiro em pós-colheita. Dissertação (Mestrado), Universidade Federal do Recôncavo da Bahia, Centro de Ciências Agrárias Ambientais e Biológicas, Cruz das Almas, BA, 2018. 86p.

26. SHARMA, R.R.; SINGH, D.; SINGH, R. Biological control of postharvest diseases of fruits and vegetables by microbial antagonists: a review. Biological Control, New Delhi,v. 50, n. 3, p. 205-221, 2009. doi:10.1016/j. biocontrol.2009.05.001

27. SHI, J.; LIU, A.; LI, X.; FENG, S.; CHEN, W. Identification of endophytic bacterial strain MGP1 selected from papaya and its biocontrol effects on pathogens infecting harvested papaya fruit. Journal of the Science of Food and Agriculture, Taian, v. 90, n. 2, p. 227-232, 2010. doi: 10.1002/jsfa.3798

28. SHI, J.; LIU, A.; LI, X.; FENG, S.; CHEN, W. Inhibitory mechanisms induced by the endophytic bacterium MGY2 in controlling anthracnose of papaya. Biological control, Taian, v. 56, n. 1, p. 2-8, 2011. doi: 10.1016/j. biocontrol.2010.09.012

29. STEMBERG, C.; CHRISTENSEN, B. B.; JOHANSEN, T.; TOFTGAARD, N. A.; ANDERSEN, J. B.; GIVSKOV, M.; MOLIN, S. Distribution of bacterial growth activity in flow-chamber biofilms. Applied and Environmental Microbiology, Lyngby, v. 65, n. 9, p. 4108-4117, 1999. doi: 10.1128/ AEM.65.9.4108-4117.1999

30. VALENZUELA, N. L.; ANGEL, D. N.; ORTIZ, D.; ROSAS, R. A.; GARCÍA, C. F. O.; SANTOS, M. O. Biological control of anthracnose by postharvest application of Trichoderma spp. on maradol papaya fruit. Biological Control, Montecillo, v. 91, p. 88-93, 2015. doi: 10.1016/j. biocontrol.2015.08.002

31. VAN BRUGGEN, A. H. C.; SEMENOV, A. M.; VAN DIEPENINGEN, A. D.; DE VOS, O. J.; BLOK, W. J. Relation between soil health, wave-like fluctuations in microbial populations, and soil-borne plant disease management. European Journal of Plant Pathology, Wageningen, v. 115, n. 1, p. 105-122, 2006. doi:10.1007/s10658-005-1250-8

32. ZHENG, M.; SHI, J.; SHI, J.; WANG, Q.; LI, Y. Antimicrobial effects of volatiles produced by two antagonistic Bacillus strains on the anthracnose pathogen in postharvest mangos. Biological Control, Taian,v. 65, n. 2, p. 200-206, 2013. doi: 10.1016/j.biocontrol.2013.02.004 